\title{
ANALISIS PENGARUH OTONOMI PENDIDIKAN TERHADAP KUALITAS BELAJAR MAHASISWA
}

\author{
Alya Jasmine Gunawan, James Parluhutan Hutabarat, Kharisma Aulia Putri, \& Nicholas \\ Amadeus Michael \\ Institut Teknologi Bandung \\ Email: 17520025@mahasiswa.itb.ac.id
}

\begin{abstract}
Abstrak
Otonomi pendidikan merupakan langkah yang diambil oleh pemerintah pusat dalam meningkatkan mutu pendidikan di Indonesia. Istilah lain dari otonomi pendidikan adalah desentralisasi pendidikan yang mengacu kepada pendidikan yang merata di seluruh daerah. Kegiatan ini sangat penting agar mahasiswa di semua daerah dapat bersaing pada jenjang pendidikan tinggi. Penelitian ini bertujuan untuk menganalisis kualitas belajar mahasiswa selama otonomi pendidikan diberlakukan. Metode pada penelitian ini adalah metode penelitian deskriptif analisis disertai penggunaan survei. Metode ini digunakan untuk mendeskripsikan secara sistematis dan faktual mengenai variabel yang akan diteliti. Selanjutnya ditunjukkan bagaimana hubungan antara variabel bebas dan variabel terikat. Hasil penelitian menampilkan peningkatan kualitas belajar mahasiswa. Salah satu program penting otonomi pendidikan adalah MBKM (Merdeka Belajar Kampus Merdeka). Program ini bertujuan mewujudkan pembelajaran otonom di kampus yang fleksibel sehingga mahasiswa dapat belajar secara interaktif dan sesuai dengan kebutuhan masing-masing. Program ini menuntut mahasiswa untuk mecari tahu metode belajar yang baru. Manfaat otonomi pendidikan pada mahasiswa adalah dapat meningkatkan keinginan belajar bagi mahasiswa. Selain itu masyarakat dapat lebih mengetahui keberadaan program-program yang telah disediakan oleh pemerintah untuk menunjang kebutuhan pendidikan di daerah agar lebih memadai.
\end{abstract}

Kata Kunci: Otonomi, Desentralisasi, Pendidikan, Mahasiswa, Pemerintah.

\begin{abstract}
Educational autonomy is a step taken by the central government in improving the quality of education in Indonesia. Another term for educational autonomy is education decentralization which refers to education that is evenly distributed throughout the region. This activity is very important so that students in all regions can compete at the higher education level. This study aims to analyze the quality of student learning during the implementation of educational autonomy. The method in this study is a descriptive analytical research method with the use of surveys. This method is used to describe systematically and factually about the variables to be studied. Furthermore, it is shown how the relationship between the independent variable and the dependent variable is shown. The results showed an increase in the quality of student learning. One of the important programs of educational autonomy is MBKM (Merdeka Belajar Kampus Merdeka). This program aims to realize flexible, autonomous learning on campus so that students can learn interactively and according to their individual needs. This program requires students to find out new learning methods. The benefit of educational autonomy for students is that it can increase students' desire to learn. In addition, the public can be more aware of the existence of programs that have been provided by the government to support educational needs in the regions to be more adequate.
\end{abstract}

Keywords: autonomy, decentralization, education, students, government

\section{PENDAHULUAN}

Pendidikan merupakan salah satu faktor penentu keberhasilan pembangunan sumber daya manusia pada sebuah komunitas. Pendidikan juga berfungsi sebagai suatu sarana pengembangan pengetahuan, keterampilan, serta penanaman karakter. Sistem pendidikan di Indonesia pun sudah berjalan dan bergantiganti sejak zaman awal kemerdekaan. Pada awal era reformasi terdapat banyak istilah otonomi yang dipakai, salah satunya adalah 
otonomi pendidikan. Otonomi pendidikan merupakan salah satu langkah kementerian pendidikan dan budaya untuk meningkatkan mutu pendidikan di Indonesia (Ridwan \& Sumirat: 2021).

Langkah ini dipilih karena beragamnya kebutuhan masyarakat di setiap daerah, terutamadi daerah terpencil Indonesia. Akibatnya, daerah sebagai fasilitator dapat menerapkan sistem pendidikannya sesuai dengan kebutuhan di daerahnya masing-masing dengan tetap mengacu pada otoritas yang diberikan oleh pemerintah pusat. Dengan adanya otonomi pendidikan, siswa maupun mahasiswa hendaknya diberikan hak untuk mendapatkan pengajaran sesuai dengan potensi, prestasi, serta kebutuhannya masing-masing (Akbal: 2017).

Mahasiswa pada suatu universitas tentunya berasal dari daerah dengan kualitas pendidikan yang berbeda. Agar kualitas pendidikan merata, pemerintah daerah dan pemerintah pusat bekerja sama membentuk berbagai program pendidikan. Program pendidikan tersebut berupa perkuliahan antar kampus dan bantuan beasiswa yang disertai tenaga pengajar bagi mahasiswa daerah di kampus. Dengan program tersebut, mahasiswa dapat memiliki pengetahuan yang lebih luas dan dapat membantu meningkatkan kualitas lulusan perguruan tinggi di Indonesia (Hartono: 2015).

Penelitian ini bertujuan untuk menganalisis beberapa subjek pendidikan otonomi. meninjau hubungan antara otonomi pendidikan dan peningkatan kualitas mahasiswa saat belajar, implementasi desentralisasi pendidikan di Indonesia belum maksimal, keefektifan pelaksanaan program otonomi pendidikan di Indonesia, hambatan atau permasalahan dalam pelaksanaan otonomi pendidikan di Indonesia, dan peran mahasiswa dalam menerapkan dan meningkatkan otonomi pendidikan. Dengan mengetahui beberapa pokok permasalahan di atas maka hasil yang didapatkan bisa menjadi evaluasi lebih lanjut pada pendidikan otonomi di Indonesia.

Adapun dengan mengenal berbagai aspek yang mendukung otonomi pendidikan, masyarakat dapat melakukan peran mereka. Peran tersebut adalah menjadi agen dalam mengajarkan generasi muda untuk dapat mengutamakan pendidikan dalam mencapai masa depan generasi muda yang lebih baik (Suwartini: 2017).

\section{METODE PENELITIAN}

Penelitian ini bersifat deskriptif analitis, yaitu mendeskripsikan data baik dari literatur serta sumber-sumber lain kemudian menganalisis data yang didapat dari survei. Teknik pengumpulan data yang digunakan dalam penelitian ini adalah data berupa studi literatur dan pengisian survei/kuesioner.

\section{HASIL PENELITIAN DAN PEMBAHASAN Hasil Penelitian \\ Hubungan Antara Otonomi Pendidikan dan Peningkatan Kualitas Belajar Mahasiswa}

Program otonomi daerah yang dianalisis terdiri dari Beasiswa Utusan Daerah (BUD), mahasiswa jalur afirmasi, MBKM (Merdeka Belajar Kampus Merdeka), KMMI (Kredensial Mikro Mahasiswa Indonesia), dan LPI (Lensa Pendidikan Indonesia). Berikut hasil dari pernyataan pengaruh program otonomi pendidikan yang diikuti oleh responden terhadap peningkatan kualitas belajar mereka. Kualitas belajar yang dimaksud tergabung dalam nilai, keaktifan, motivasi, dan prestasi dari responden. 


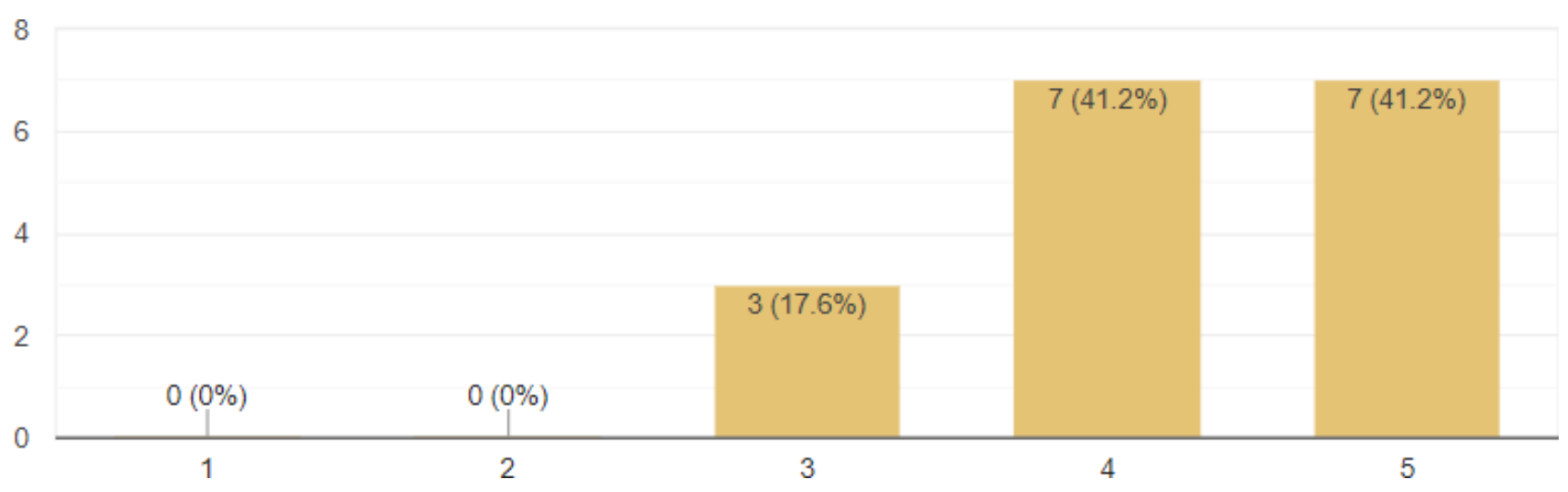

Gambar.1 Grafik Hubungan Program Otonomi Pendidikan terhadap Peningkatan Kualitas Belajar

Grafik memiliki karakteristik nilai 1 yang merepresentasikan tidak berpengaruh dan nilai 5 merepresentasikan sangat berpengaruh. Bagi responden yang telah melewati program otonomi daerah ini banyak dampak positif yang didapatkan, yaitu:

1. Membantu biaya hidup dan pendidikan mahasiswa

2. Meningkatkan pengalaman ditambah dengan softskill dan hardskill

3. Menambah relasi antar kampus dan antar daerah guna menambah sudut pandang proses belajar mengajar antar kampus

4. Membentuk mahasiswa menjadi pribadi yang memiliki etika dan etos kerja yang lebih matang sebagai bekal di dunia kerja

5. Menanggulangi pemerataan pendidikan di kalangan mahasiswa minim pendidikan semasa di daerah asal

Adapun respon dari mahasiswa yang
tidak mengikuti program otonomi
pendidikan dengan mengandalkan
informasi dari keluarga, teman, keluarga,
instansi pendidikan, situs web, dan media
sosial. Terdapat respon seperti di bawah ini
dengan kriteria grafik sama dengan
responden mengikuti program otonomi
pendidikan.

30

20

$23(52.3 \%)$

.

10

0

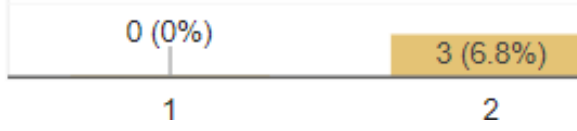

$4(9.1 \%)$

3

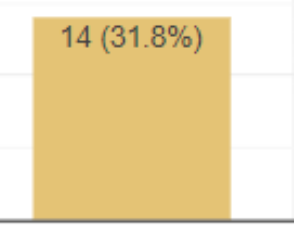

5

\section{Gambar.2 Grafik Hubungan Program Otonomi Pendidikan terhadap Peningkatan Kualitas Belajar Mahasiswa Tidak Mengikuti Program Otonomi Pendidikan}

Berdasarkan grafik beberapa responden masih ragu akan relasi dari peningkatan kualitas belajar sebagai bagian dari dampak program otonomi pendidikan. Adapun beberapa alasan yang melandasi tanggapan di atas, yaitu: 
1. Mendapatkan biaya kuliah dan biaya hidup dengan nominal jutaan

2. Tidak menentukan dengan alasan program pendidikan dari pusat sudah cukup dalam meningkatkan kualitas belajar

3. Kualitas belajar belum tentu meningkat tetapi biaya hidup dan kuliah pasti dapat tercukupi

4. Karena banyaknya relasi maka kesempatan untuk belajar lebih banyak juga semakin besar. Alhasil ada motivasi untuk semakin berkembang

Bagi mereka yang telah mengikuti program otonomi pendidikan banyak merasakan dampak positif dalam pengingkatan kualitas belajar. Hal ini terbukti dari $82 \%$ responden menjawab berpengaruh. Akan tetapi, program ini kurang berpengaruh dalam peningkatan kualitas belajar bagi mereka yang belum terlibat langsung. Hal ini terbukti dari 16\% dari yang tidak mengikuti menjawab kurang berpengaruh dan biasa saja. Hasilnya dengan adanya program otonomi pendidikan banyak mahasiswa yang memiliki kesempatan berkuliah. Sehingga

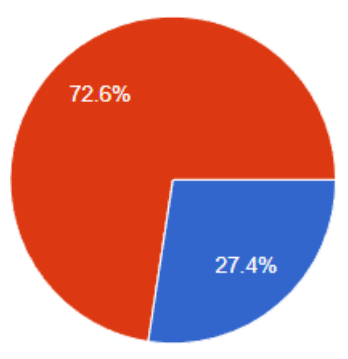

dapat dinyatakan otonomi pendidikan dan aktivitas mahasiswa sangar berhubungan (Kunci: 2010).

\section{Pembahasan \\ Implementasi Desentralisasi Pendidi- kan Indonesia Belum Maksimal \\ Pelaksanaan otonomi pendidikan erat kaitannya dengan prinsip desentralisasi sistem pendidikan. Program yang diselenggarakan masih belum maksimal diikuti oleh mahasiswa. Hal ini terbukti dengan banyaknya mahasiswa yang masih belum mengetahui bahwa terdapat banyak program otonomi yang telah ada saat ini. Program ini dijalankan dengan tujuan agar Indonesia dapat menjadi negara maju yang mempunyai potensi alam dan potensi manusia serta potensi kebudayaan (Dosen: 2018). \\ Berdasarkan survei melalui kuesioner yang kami lakukan dari total 62 responden didapat presentasi yang mengikuti atau pernah mengikut program otonomi yang sebelumnya dijelaskan hanya $27 \%$ saja. Presentasi ini dapat dilihat pada diagram berikut.}

Pernah/sedang

Tidak pernah

\section{Gambar.3 Grafik Hubungan Implementasi Desentralisasi Pendidikan terhadap Partisipasi Mahasiswa}

Pada diagram terdapat 17 responden yang mengikut dan 45 lainnya tidak pernah mengikuti program otonomi pendidikan. Berdasarkan hasil analisis kami melalui alasan yang diberikan banyak dari responden yang masih mengalami kekurangan informasi dalam mengakses berbagai program yang telah disediakan.
Terdapat kesan buruk seperti sulit untuk lolos, waktu proses yang lama, dan banyak lagi.

Setelah tahu program otonomi pendidikan, banyak dari responden yang merasa termotivasi untuk selanjutnya mengikut program otonomi pendidikan. Hal ini dipastikan pada sesi pertanyaan 
berikutnya responden ditanyakan apabila ada kemungkinan mereka mengikuti program otonomi pendidikan. Berikut

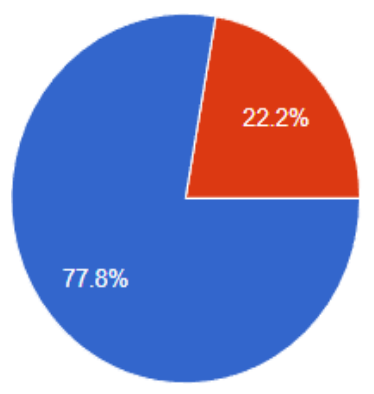

representasi grafik hasil kuesioner pada mahasiswa.

Ya, tertarik

Memang tidak tertarik

Gambar.4 Grafik Hubungan Implementasi Desentralisasi Pendidikan terhadap Ketertarikan Mahasiswa

Dari total 45 orang responden, 35 responden menyatakan tertarik dengan program otonomi pendidikan . Alasan yang didiperoleh diantaranya, ingin menambah pengalaman, mencoba lingkungan belajar yang baru, bertujuan menambah semangat belajar, ingin merasakan perbedaan metode belajar antar kampus, mencari peluang kerja atau magang yang bagus dalam kontribusi antar kampus, dan terakhir karena merasa akan terbantu dalam memenuhi biaya kuliah dan biaya hidup. Sisanya yang tidak tertarik menyatakan ingin berkuliah di luar negeri, tidak nyaman dengan metode belajar daring yang dijalani, belum merasa membutuhkan dalam segi dana dan pengalaman, beberapa tidak memenuhi kriteria yang disyaratkan oleh pihak penyelenggara program, dan beberapa memilih tanpa alasan.

\section{Keefektifan Pelaksanaan Program Otonomi Pendidikan Di Indonesia}

Indonesia merupakan negara majemuk baik dalam kebudayaan, sosial, ekonomi dan sebagainya. Berbagai perbedaan tersebut dijadikan sensitivitas yang berpotensi memicu konflik antar daerah. Kekerasan antar kelompok yang meledak secara sporadis di berbagai kawasan Indonesia menunjukkan betapa rendahnya rasa toleransi akan perbedaan
(Yunita: 2021) (Nurgiansah, 2021). Keefektifan dari program dapat diperoleh dari survei yang telah disebar. Terdapat dua sisi pengisi survei, untuk yang pernah atau sedang mengikuti program otonomi pendidikan dan yang belum pernah mengikuti program otonomi pendidikan.

Berdasarkan analisis yang kami dasarkan dari survei dan literatur, didapatkan bahwa responden yang pernah mengikuti program otonomi pendidikan melihat bahwa program yang dijalankan cukup berpengaruh terhadap peningkatan kualitas belajar mereka karena berbagai macam alasan, salah satunya adalah mahasiswa dapat belajar sesuai dengan kebutuhan mahasiswa. Para responden juga merasa bahwa dengan adanya otonomi pendidikan, wadah mereka untuk mengembangkan diri menjadi lebih luas dan bervariasi.

\section{Hambatan atau Permasalahan dalam Pelaksanaan Otonomi Pendidikan di Indonesia}

Peningkatan kualitas sumber daya melalui pendidikan merupakan prioritas nasional. Hal ini dikarenakan pendidikan dipandang sebagai faktor penentu keberhasilan pembangunan manusia baik pengetahuan, keterampilan, nilai, dan kebudayaan. Akan tetapi, pelaksanaan 
otonomi pendidikan di Indonesia sering kali tidak terlepas dari permasalahan dan hambatan. Kebijakan yang muncul dari kebijakan lama atau bisa disebut sebagai pembaruan kebijakan bukan berarti tidak menimbulkan masalah. Kebijakan progresif sekalipun pada awal penerapan juga ditemukan banyak kendala, termasuk kebijakan tentang otonomi pendidikan (Purba: 2010).

Berdasarkan hasil survei yang telah dilakukan pada 62 mahasiswa, 20 orang berpendapat bahwa faktor yang menghambat otonomi pendidikan yaitu kurangnya sumber daya manusia dalam pemenuhan fasilitas pendidikan, 16 orang menyatakan lemahnya motivasi belajar dari mahasiswa juga turut menghambat otonomi pendidikan, sedangkan 16 orang lainnya beranggapan bahwa faktor penghambat berasal dari pemikiran sebagian masyarakat yang merasa

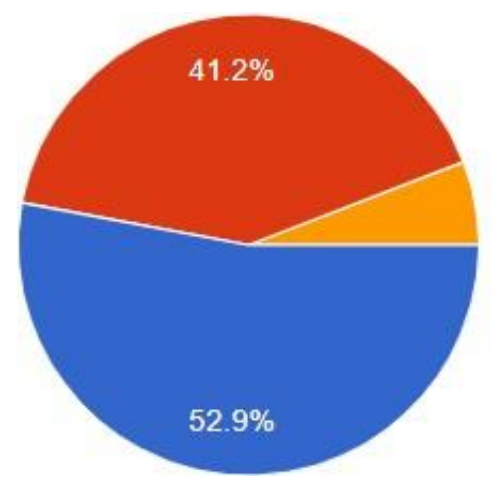

\section{Gambar.5 Grafik Kesulitan Mahasiswa dalam Mengakses Program Otonomi Pendidikan}

Pelaksanaan otonomi pendidikan masih belum sepenuhnya berjalan sesuai dengan yang diharapkan. Hal ini disebabkan karena pranata sosial maupun ekonomi masih belum siap mengurus kepentingannya masing-masing. Otonomi pendidikan akan memberi efek terhadap kurikulum, efisiensi administrasi, pendapatan dan biaya pendidikan, serta pemerataan (Junaidi: 2021). Beberapa faktor yang menyebabkan pelaksanaan
Informasi yang tidak memadai

Proses administrasi yang menyulitkan

Kuota tidak mencukupi

pendidikan tinggi kurang dibutuhkan dan memilih untuk langsung bekerja, sisanya berpendapat bahwa pemerintah kurang mendukung pelaksanaan kegiatan di bidang pendidikan pada daerahnya (Ratu: 2021) (Nurgiansah, 2020).

Jika melihat berdasarkan pengalaman mahasiswa, masih terdapat beberapa kendala dalam program otonomi pendidikan yang telah dilaksanakan, $52.9 \%$ menyatakan bahwa mereka kesulitan dalam mendapatkan informasi yang memadai perihal kebijakan yang telah disediakan. Sedangkan 41.2 \% responden menyatakan jika mereka merasa proses administrasi yang disediakan cukup menyulitkan. Lainnya menyatakan jika kuota atau dari kebijakan yang telah disediakan masih tidak mencukupi mengingat jumlah mahasiswa yang sangat banyak. 
masyarakat dalam pengelolaan pendidikan.

4. Kondisi tiap daerah yang tidak memiliki kekuatan yang sama dalam penyelenggaraan pendidikan karena adanya perbedaan sarana, prasarana, dan dana yang dimiliki.

\section{Peran Mahasiswa dalam Menerapkan dan Meningkatkan Otonomi Pendidikan}

Pada dasarnya, masalah mengenai pelaksanaan otonomi pendidikan bukan hanya sekadar berfokus anggaran, manajemen, ataupun kualitas SDM. Pelaksanaan otonomi pendidikan dalam meningkatkan mutu pendidikan di Indonesia juga perlu adanya perhatian dari mahasiswa itu sendiri (Nurgiansah, 2018). Terlebih lagi mahasiswa selaku konsumen pendidikan yang sedang menempuh pendidikan tinggi. Permasalahan seputar pendidikan ini dapat disumbangkan oleh mahasiswa terhadap pihak yang terkait dan melakukan kontrol terhadap kebijakan pemerintah dalam dunia pendidikan.

Sudah menjadi keharusan bahwa mahasiswa harus turut aktif dalam menyoroti kebijakan yang dilaksanakan dalam otonomi pendidikan ini. Mahasiswa memiliki kontribusi yang besar dalam meningkatkan kinerja otonomi pendidikan. Pengembangan potensi diri sebagai kesadaran akan hakikat pendidikan yang mendasar, melakukan kontrol kebijakan pemerintah terhadap penentuan arah dan karakteristik pendidikan, serta berupaya untuk memenuhi kebutuhan akan perbaikan dari sebuah sistem pendidikan di Indonesia. Banyak hal yang dapat dilakukan oleh mahasiswa dalam memaksimalkan otonomi pendidikan yang sedang dilaksanakan terlebih lagi jika sudah mengetahui permasalahan dan hambatan yang terjadi. Misalnya seperti meningkatkan kesadaran masyarakat sekitar akan pentingnya pendidikan, memperkuat motivasi dalam belajar dan memaksimalkan fasilitas yang didapatkan sebaik mungkin, atau dapat menjadi pendukung dalam meningkatkan sumber daya manusia baik dalam meningkatkan kualitas diri ataupun sebagai tenaga pengajar (Ambarita: 2021).

Otonomi pendidikan tidak hanya semata-mata tanggung jawab pemerintah. Perlu ada dukungan dari semua pihak, baik pemerintah maupun masyarakat, terutama mahasiswa. Mahasiswa sejatinya merupakan motor penggerak utama perubahan. Dengan intelektualitasnya, peran strategis mahasiswa akan selalu dibutuhkan. Selain itu, pengertian otonomi pendidikan sesungguhnya terkandung makna demokrasi dan keadilan sosial, artinya pelaksanaan dilakukan secara demokrasi sehingga tujuan yang diharapkan dapat diwujudkan dan pendidikan diperuntukkan bagi kepentingan masyarakat sesuai dengan cita cita bangsa dalam mencerdaskan bangsa (Mahmud: 2012).

\section{KESIMPULAN}

Berdasarkan hasil penelitian mengenai pengaruh otonomi pendidikan terhadap kualitas belajar mahasiswa, maka kami menarik kesimpulan bahwa otonomi pendidikan di Indonesia berpengaruh positif pada mahasiswa-mahasiswa yang mengikuti program otonomi pendidikan yang telah ada. Hal ini dilakukan walau pelaksanaan otonomi pendidikan itu sendiri masih belum maksimal. Hasil penelitian kami juga menunjukkan bahwa jumlah ketertarikan mahasiswa untuk mengikuti program otonomi pendidikan lebih banyak dari jumlah mahasiswa yang memang mengikuti, membuktikan banyaknya mahasiswa yang masih belum sepenuhnya mengetahui adanya berbagai program otonomi pendidikan ini. Analisis ini juga sejalan dengan banyaknya jumlah mahasiswa yang menyetujui kurang memadainya informasi yang mereka 
dapatkan sebagai kendala terbesar saat mengakses program otonomi pendidikan. Dengan penelitian mengenai pengaruh otonomi pendidikan terhadap kualitas belajar mahasiswa ini, diharapkan kami dapat lebih mengerti atas dampak otonomi pendidikan Indonesia yang kami sadari masih belum terlaksanakan dengan maksimal.
Terima kasih kami sampaikan kepada Tuhan Yang Maha Esa dan kepada Dr. Harry Nuriman, M.Si. selaku dosen pembimbing kami dalam mata kuliah Pancasila dan Kewarganegaraan, semua mahasiswa kampus di Indonesia sebagai responden, dan pihak-pihak yang membantu kami menyelesaikan laporan penelitian ini.

\section{DAFTAR PUSTAKA}

Akbal, M. (2017). HARMONISASI KEWENANGAN ANTARA PEMERINTAH PUSAT DAN DAERAH DALAM PENYELENGGARAAN OTONOMI DAERAH. SUPREMASI: Jurnal Pemikiran, Penelitian Ilmu-Ilmu Sosial, Hukum Dan Pengajarannya, 11(2). http://103.76.50.195/supremasi/article/view/2800

AMBARITA, B. (2017). STRATEGI PERGURUAN TINGGI DALAM MENINGKATKAN MUTU PENDIDIKAN. GENERASI KAMPUS, $2(1)$. https://jurnal.unimed.ac.id/2012/index.php/gk/article/view/6948

Dosen, A., \& Al-Karimiyyah, S. (2018). ANALISIS PROBLEMATIKA OTONOMI PENDIDIKAN. Jurnal Kariman, 6(1), 99-108. https://doi.org/10.52185/KARIMAN.V6I1.14

HARTONO, H. (2015). OTONOMI PENDIDIKAN. POTENSIA: Jurnal Kependidikan Islam, 1(1), 51-66. https://doi.org/10.24014/POTENSIA.V1I1.1241

Kunci, K., Daerah dan Pendidikan, O., Prodi Pendidikan Jasmani Dan Rekreasi -STKIP Bina Bangsa Getsempena, D., Tgk Chik Di Tiro, J., \& Aceh, B. (2010). OTONOMI DAERAH DAN OTONOMI PENDIDIKAN. Visipena, 1-9. https://doi.org/10.46244/VISIPENA.V1I2.25

Mahmud My, M. M. (2012). Otonomi Pendidikan (Sebuah Tinjauan Terhadap Peran Masyarakat). Al-Fikrah: Jurnal Kependidikan Islam IAIN Sulthan Thaha Saifuddin, 3, 56820. https://doi.org/10.0/CSS/ALL.CSS

Nurgiansah, T. H. (2018). Pengembangan Kesadaran Hukum Berlalu Lintas Siswa Melalui Model Pembelajaran Jurisprudensial Dalam Pendidikan Kewarganegaraan (Studi Kasus di SMK Bina Essa Kabupaten Bandung Barat Kelas X Administrasi Perkantoran). Tesis. Repository Universitas Pendidikan Indonesia, Oktober. http://ieeeauthorcenter.ieee.org/wpcontent/uploads/IEEE-Reference-

Guide.pdf\%0Ahttp://wwwlib.murdoch.edu.au/find/citation/ieee.html\%0Ahttps://doi.or g/10.1016/j.cie.2019.07.022\%0Ahttps://github.com/ethereum/wiki/wiki/White-

Paper\%0Ahttps://tore.tuhh.de/hand

Nurgiansah, T. H. (2020). Filsafat Pendidikan. In Banyumas: CV Pena Persada.

Nurgiansah, T. H. (2021). Pendidikan Pancasila. In Solok: CV Mitra Cendekia Media.

Pendidikan, O., Pembiayaan, D., Junaidi, P., Dosen, A., Uin, F., Utara, S., William, J., Pasar, I., \& Medan, V. (2018). OTONOMI PENDIDIKAN DAN PEMBIAYAAN PENDIDIKAN. SABILARRASYAD: Jurnal Pendidikan Dan Ilmu Kependidikan, 3(2), 27-38. http://jurnal.dharmawangsa.ac.id/index.php/sabilarrasyad/article/view/478

Purba, S. (2010). PENINGKATAN KUALITAS SUMBER DAYA MANUSIA MELALUI SEKTOR PENDIDIKAN.

Ratu, D., Khasanah, A. U., Pramudibyanto, H., \& Widuroyekti, B. (2020). Pendidikan Dalam Masa
Pandemi
Covid-19.
Jurnal
Sinestesia,
$10(1)$
41-48. 
https://sinestesia.pustaka.my.id/journal/article/view/44

Ridwan, I., \& Sumirat, I. R. (2021). KEBIJAKAN DESENTRALISASI PENDIDIKAN DI

ERA OTONOMI DAERAH. Jurnal Pendidikan Karakter JAWARA (Jujur, Adil, Wibawa, Amanah, Religius, Akuntabel), hhttps://jurnal.untirta.ac.id/index.php/JAWARA/article/view/11611

Suwartini, S. (2017). Pendidikan Karakter dan Pembangunan Sumber Daya Manusia Keberlanjutan. TRIHAYU: Jurnal Pendidikan Ke-SD-An, 4(1). https://doi.org/10.30738/TRIHAYU.V4I1.2119

Triana, I. D. S., \& Iskatriah, I. (2021). IMPLEMENTASI NILAI-NILAI PANCASILA DI DALAM MENCIPTAKAN PENDIDIKAN KARAKTER YANG KUAT BAGI BANGSA INDONESIA DALAM TATANAN HUKUM NASIONAL. Jurnal Pendidikan Kewarganegaraan Undiksha, 9(2), 356-567. https://ejournal.undiksha.ac.id/index.php/ШPP/article/view/34138

Yunita, T. (2021). PENDIDIKAN KEWARGANEGARAAN DALAM MENGUATKAN INTEGRASI BANGSA. Jurnal Pendidikan Kewarganegaraan Undiksha, 9(2), 282-290. https://doi.org/10.23887/JPKU.V9I2.34132 